\title{
Therapy of Social-Emotional Development on Autism Spectrum Disorder Diagnosed Child in Inclusive Early Childhood Education and Development Yogyakarta, Indonesia
}

\author{
Wantini \\ Universitas Ahmad Dahlan, Indonesia \\ Sutrisno and Casmini \\ Universitas Islam Negeri Sunan Kalijaga Yogyakarta, Indonesia \\ Suyatno \\ Universitas Ahmad Dahlan, Indonesia
}

\begin{abstract}
This research aims to examine the symptoms of socialemotional development deficits using ASD in inclusive ECED. According to the study, schools utilize this therapeutic method to improve their condition and positively impact on the social development of children. This is a qualitative research with case study design using the psychological approach of special needs children and data was collected through observation, deep interview, and documentation. Data was collected and analyzed using the Miles \& Huberman interactive inductive technique, which reduces, displays, and concludes drawing. The results therefore showed the symptoms of social-emotional development deficit to cover the ability to communicate, socialize, and behave, the therapeutic method used include modern psychological, medical, and religious therapies, and the application of these therapies by each ECED was found to improve the children's social-emotional development on communication, socialization, and behaviors. This research's discovery shows the importance of school-based social-emotional development intervention on a child in inclusive ECED.
\end{abstract}

Keywords: Therapeutic method, Social-emotional development, Autism spectrum disorder, and inclusive ECED.

\section{Introduction}

This study examines the therapy of early childhood emotions on social development conducted in some Inclusive Early Childhood Education and 
Development (ECED) in Yogyakarta. In the last decade, this has become important and urgent as the number of ASD children tend to increase yearly. The results of several research show the number of ASD has increased tremendously over the years and autism remains an enigma (Vinanti et al., 2015). The Center for Disease Control and Prevention (2016) reported more than $9.4 \%$ of children aged 2-17 years experienced ASD and this trend has been predicted to continue due to the increment in the factors causing the disorder. ASDs are often experienced more than once in the same family and for identical twin, the concordance rate for a disorder on the autism spectrum is more than $90 \%$ and $60 \%$ for autism (Veenstra et al., 2003). Furthermore, more than $10 \%$ of siblings diagnosed with ASD experiences development deficit and autism has been reported to be contagious to the closely related family (Constantino et al., 2006; Dawson et al., 2002; Landa \& Mayer, 2006; Zwaigenbaum et al., 2005).

The latest research indicates improvement in curing a child with ASD in the past few decades was mainly due to the application of behavioral analysis (Matson et al., 2007). Moreover, a number of qualitative researches tried to investigate the effectiveness of social skill therapy for children diagnosed with ASD (Hwang \& Hughes, 2000; Rogers, 2000; McConnell, 2002). The result of 16 studies involving social skill programming conducted by Hwang and Huges (2000) showed the programs to be effective in bringing positive and promising impacts on the social and communication of the affected children.

Furthermore, Bauminger (2002) evaluated the effectiveness of cognitive behavior therapy for 7 months to facilitate social-emotional and interaction understanding from 15 high functioning children (with the age within 8-17 years old) with autism. The intervention conducted was focused on interpersonal problemsolving skills, social interaction, and effective knowledge. The result showed three signs of progress in three types of intervention to include the dimension of social interaction where they developed the ability to start a positive social interaction with the same aged friends in sharing experiences, maintaining eye contacts, and interests; problem-solving skill, they gave a more relevant solution and less non-social solution in many different situations; and for emotional knowledge, they gave more example of specific and complex emotion, and involved audience frequently in different emotions compared to their situation prior to the intervention.

From a different perspective, Stoneman (2005) explained a number of research works based on the premise that siblings with ASD give a negative impact on the family. However, other researchers (McMahon et al., 2001; Singhi et al., 2002; Verte et al., 2003) showed there is no significant difference between children having siblings with ASD in the aspects of the focus of control, self-concept, and self-efficacy. The research of Mahoney and Perales (2003) further revealed that a relationship focused intervention gives optimism to improve social-emotional development.

Moreover, high responsiveness of the parents has been reported to make it possible for these children to learn developmental behavior needed to improve social skills function. Siller and Sigmund (2002) further stated that the 
responsiveness of the mother aids the communication of the children at the ages of one, ten, and twelve years old.

Bellini et al. (2007) and Otero et al. (2015) developed a meta-analysis on schoolbased social skills intervention for children with ASD and the results showed it is effective in achieving the purpose for which it was created. Bellini et al. (2007) further explained that despite the need to provide effective school-based social intervention, only limited researchers are studying its effectiveness on a specific population of the school.

Downs and Smith (2004) revealed that a child with ASD undergoes hardship when trying to be cooperative with others and also has below average ability to understand emotions and special behavior compared to normal children. Piickles et al. (2000) and Rutter (2000) recorded from an adult who has problems with ASD diagnosed child that $20 \%$ of them have communication and social function hindrance. Furthermore, diminishing positive influence is also one of the indications of atypical development of these children (Osterling et al., 2002). Wimpory et al. (2000) also revealed they experience difficulty on getting close to others individually or in adjacent to other social objects. However, these socialemotional development hindrances eventually lead to those in other aspects such as poor academic achievement, exclusion from their friends, depression, anxiety and other social illnesses (Tantam, 2000; Bellini, 2006; Weish et al., 2001) and the lack of adequate intervention would lead to continuous sustenance of the problems for a long period (Howlin et al., 2000).

However, even though social skills hindrance always sticks to the individual with ASD, some children given a proper therapy shows quite encouraging development (Hume et al., 2005). Several therapy programs (such as speech, occupational, and behavioral therapies) conducted have given a positive impact on the social skill of children with ASD by improving their social, emotional and cognitive development. Therefore, an effectiveness social skill program should be an integral component to the education of these children (Trianes \& Fernández-Figarés, 2001; Torres et al., 2003).

Therefore, it is important to conduct qualitative research to uncover the development deficit experienced by children with ASD in four inclusive ECED in Yogyakarta, Indonesia along with the therapeutic method used by the institution to develop social-emotional aspects. Therefore, this study is expected to determine a therapeutic method for effectiveness social-emotional in inclusive ECED and enriching references for educational practitioners, especially in the level of early childhood education.

Based on the backgrounds described, this research was meant to answer the three questions below: 1) What type of social-emotional deficit is experienced by children diagnosed with ASD in four inclusive ECED in Yogyakarta? 2) What type of therapeutic method is used by the schools to improve the socialemotional development of children with ASD? 3) What is the impact of the therapeutic method on the social-emotional development of children with ASD? 


\section{Theoretical Framework}

\subsection{Social-Emotional Development in Early Age Children}

Autism is usually used to indicate a psychosis in unique and stand-out children, and often times referred to as Kanner Syndrome. It mostly characterized by a hollow face expression showing the person is daydreaming, lost in thought and hard to communicate with (Bratton et al., 2005) as well as decreasing social function (Myles et al., 2005; Rogers, 2000).

The early symptoms mostly observed include lack of eye contacts and interest to interact with others. In normal development, a child may start interacting with the mother at 3-4 months and when stimulated by shacking, ringing toys and conversations, the child responds and reacts with babble and movements (El Achkar \& Spence, 2015). This is, however, lacking in children with autism such that they act indifferent by rejecting interaction with others. Pilowsky et al. (2004) further reported siblings of these children also have the tendency to experience some hindrance to their social-emotional development which may lead to stress. Development is a process of growing in a more psychologically advanced direction while growth is the enhancement in number, size, and important meanings; it is simply a step of physical development (Susanto, 2011).

Social-emotional development for children in early ages develops quickly in selfconfidence, empathy, curiosity, linguistic competence for communication and the ability to relate with other people. The curriculum developed by Indonesian BSNP (national education standards body) for these children in 2013 shows the indicator for social-emotional development to be as shown in Table 1.

Table 1. Early Ages Children Social-Emotional Development Indicator

\begin{tabular}{|c|c|}
\hline Age(s) & Developmental Achievement Levels \\
\hline \multirow[t]{8}{*}{$4-<5$ years old } & 1. Showing independent attitude in choosing activities \\
\hline & 2. Willing to share, help, and assist friends \\
\hline & $\begin{array}{l}\text { 3. Showing enthusiasm in playing competitive games with positive } \\
\text { manners }\end{array}$ \\
\hline & 4. Can control feelings \\
\hline & 5. Obeying the rule in a game \\
\hline & 6. Showing self-confidence \\
\hline & 7. Taking care of self and the environment \\
\hline & 8. Appreciating others \\
\hline \multirow[t]{9}{*}{$5-\leq 6$ years old } & 1. Being cooperative with friends \\
\hline & 2. Showing tolerance \\
\hline & $\begin{array}{l}\text { 3. Expressing emotion according to conditions (happy-sad- } \\
\text { enthusiast) }\end{array}$ \\
\hline & 4. Knowing manners applying to society \\
\hline & 5. Understanding rules and discipline \\
\hline & 6. Showing empathy \\
\hline & 7. Persistent \\
\hline & 8. Proud of something self-made \\
\hline & 9. Appreciating excellence \\
\hline
\end{tabular}




\subsection{Therapeutic Method for the Social-Emotional Development of Children with ASD}

Therapy is a procedure to cure or lighten a sickness and it contains a set of procedure to ideally generate a permanent change in patients. It is, therefore, a treatment conducted on an individual going through a certain hindrance.

Moreover, the developmental therapy is an improvement on the developmental stimulus planned specifically to fulfill the need of children individually, in accordance with their speed and progress and this helps them conduct activities needed to develop and study. However, early stimulation means giving every chance to children to get experience from exploring and playing with things around them. This is important to make a healthy growth for their body and the mind. Generally, stimulation comes naturally and conveniently through people or things around them. Therefore, children with development hindrance need extra stimulation, therapy, and exhilarating special activity to study and starting at a very young age makes it possible to lessen their developmental deficit.

One of the methods to observe and diagnose behavior in counseling children with difficulties in physical, emotional, intellectual and mental development is the play pattern and it involves two different approaches which are 1) Active play therapy, which involves weighing on a concrete problem occurring at a specific time in the kid's life and reducing the amount of emotion perceived to be hard for them such as fear and aggression, and 2) Passive play therapy, which involves allowing the children to play freely with their play tools (Delphi, 2006).

Bratton et al. (2005), however, explained that play therapy is used to treat emotional and behavioral problems due to its unique responses and varieties of development needed. Schaefer (2002) defined the concept as an interpersonal process used by a therapist through the application of force to cure as well as the use of games as a medium to curb psychological hindrance and as a preventive action for the future. Moreover, play therapy tries to let children solve their own frustration in a media where a therapist has the ability to analyze their conflict and the solution.

Furthermore, Matson and Wilkins (2007) defined social skills as an interpersonal response by verbal and non-verbal communication which makes it possible for children to adapt to their environment. The main goal of social skill program for children with ASD is to train them on how to maintain eye contact, talk in a right tone, right facial expression, the number of words to be said, precise motoric movements, and the right content of conversation, for example, saying "thanks" and "help" in the right manner.

Erikson (1997) elaborated the psychosocial theory by showing the individual development phase to be the cycle of life formed by social influence through interactions aiding the maturity of an individual physically and psychologically. Generally, the main point of psychosocial theory is that (1) emotional development goes with physical growth (2) there is an interaction between physical growth and psychological development, (3) there is same regularity between physical growth and psychological development, (4) while going towards maturity, the psychological, biological, and social development unites, 
(5) children are organism, ego, and social creature combined altogether, and (6) human's development from birth up to death is divided into phases, with developmental tasks of each phase.

\section{Methods}

\subsection{Research design}

This is a descriptive qualitative research conducted using a scientific background with the researcher being the main instrument and data were analyzed inductively. Moreover, an educational psychological approach for special needs children was used because of its correspondence with the behavior and development of the children in a phenomenon or an educational environment, especially with respect to the optimization of early age kid's development. It was conducted by observing education object aged 6 and under as well as children with disabilities.

\subsection{Participants}

The subjects for the research were 12 persons consisting of 2 doctors in child's growth and development, 2 psychologist, 4 teachers, and 4 students studying in 4 inclusive ECED in Yogyakarta including PAUD Inklusif Fakultas Psikologi UGM, PAUD Inklusif Ahsanu 'Amala, TK ABA Nitikan, and TK Pedagogia UNY. The four ECED were selected using the purposive sampling technique using the best inclusive education practices in Yogyakarta. In determining the subject, the researcher agreed with the submission of Starks and Trinidad (2007) who stated that in qualitative researches, big sample is not a compulsion to produce the required data, because one can gather much description and idea. The demographics of the research subjects are explained in Table 2 and Table 3.

Table 2. Demographics of research subjects $(N=4)$

\begin{tabular}{lclll}
\hline $\begin{array}{l}\text { Name } \\
(\text { Initials })\end{array}$ & Age(In years) & Gender & Position & Institution \\
\hline DN & 4 & Male & Early age child & $\begin{array}{l}\text { PAUD Psikologi } \\
\text { UGM }\end{array}$ \\
\hline AT & 5 & Male & Early age child & TK Pedagogia UNY \\
\hline DW & 5 & Female & Early age child & PAUD Ahsanu \\
& & & & Amala \\
\hline AD & 4 & Female & Early age child & TK ABA Nitikan \\
\hline
\end{tabular}

Table 3. Demographics of therapist $(\mathrm{N}=8)$

\begin{tabular}{lclll}
\hline $\begin{array}{l}\text { Name } \\
\text { (Initials) }\end{array}$ & $\begin{array}{c}\text { Age(In } \\
\text { years })\end{array}$ & Gender & Position & Institution \\
\hline $\mathrm{Hs}$ & 37 & Female & $\begin{array}{l}\text { Child growth and development } \\
\text { doctor }\end{array}$ & PAUD Psikologi UGM \\
\hline $\mathrm{Nw}$ & 45 & Female & $\begin{array}{l}\text { Child growth and development } \\
\text { doctor }\end{array}$ & TK Pedagogia UNY \\
\hline $\mathrm{Mps}$ & 30 & Female & Psychologist & PAUD Psikologi UGM \\
\hline $\mathrm{Ldy}$ & 33 & Female & Psychologist & TK Pedagogia UNY \\
\hline $\mathrm{Wl}$ & 27 & Female & Teacher & PAUD Psikologi UGM \\
\hline $\mathrm{Cu}$ & 24 & Female & Teacher & TK Pedagogia UNY \\
\hline $\mathrm{Sa}$ & 26 & Female & Teacher & PAUD Ahsanu Amala \\
\hline Js & 25 & Female & Teacher & TK ABA Nitikan \\
\hline
\end{tabular}




\subsection{Data Collection}

The data used were collected through the use of three methods which are deep interview, observation, and documentation. Research guidelines are developed based on the theoretical framework produced. This guideline contains key indicators of each component studied, which were used to conduct in-depth interviews. Interview was conducted on the teachers, doctors, and psychologists in order to gather information about the therapeutic methods, early detection models, process and the method of social-emotional developmental therapy, as well as the report to the developmental therapy, inclusive class model for therapy. The result of the therapy on social-emotional development and the results obtained were written in the form of field notes (Creswell, 2013). However, the interview was conducted with respect to the interview theory framework. Furthermore, the observation was conducted on the therapeutic process performed by the teachers, doctors, and psychologists as well as the behavior of the children in order to identify the symptoms shown by children with ASD. It was also conducted on the learning activities and its infrastructures and educative playing instruments. The documentation was used to track the documents relating to the social-emotional development of ASD diagnosed child and the method used by the teacher, doctors, and the psychologist in the school.

\subsection{Data Analysis}

Data analysis techniques used include data reduction, displays, and conclusion. The process started with the processing of the interview transcript and rereading the result of the interview in order to become more familiar and fully understand the information (Creswell, 2008; Liamputtong, 2009). The data from observation and documentation were also processed using those three steps. The results of the interview were quoted as an example and an illustration from each theme was made in this research (Fine et al. 2000; Simons, 2009).

\section{Findings}

The display of the results was explained in three sub-topics of social-emotional development deficit experienced by children, developmental therapy method used, and the impact on the social-emotional development after the therapy.

\subsection{Research Subject DN (PAUD Psikologi UGM)}

\subsubsection{Social-emotional development deficit}

Based on the result of the interview with $\mathrm{HN}$, doctor on child growth and development in PAUD Psikologi UGM, it was observed that:

"DN undergoes developmental hindrance in emotional aspect with the symptoms such as a lot of crying, anger, overwhelming temper, and only wants to eat rice with chicken and crisp. Moreover, DN got a nose bleed easily when tired, and eats too much chocolate which is not balanced with the rice consumed."

The interview result above is also supported by the information from the documentation the researcher obtained which shows that DN cries almost every day, shows anger management issue, overwhelming temper, and nose bleeds. 


\subsubsection{The Therapy obtained by DN in school}

The therapy applied to DN includes medical, speech, and occupational therapies. According to the interview with DN, the result is as follows:

"The medical therapy is conducted to maintain the body in order to stay healthy and stable by child growth and development doctor while modern psychological therapy is conducted by the psychologist and the teachers and when the child cries the teacher hugs him. Moreover, learning activities were mainly conducted to create independence and speech therapy by blowing balloons and candles. The children have gotten used to drinking using straws. Occupational therapy is also conducted to improve DN's lack of motoric development because his movement is considered rough and inflexible compared to other children in the same age category."

Interview with Mps, a psychologist in PAUD psikologi UGM:

"The teacher trains DN to convey feelings by using a short phrase and one to two words clearly and repeatedly, for example, the word "help" (to-long) was simplified to make the child say help with the intention to ask for help to do something such as asking for water from others. DN was also trained on words such as "sad", "hurt", "angry" to convey his feelings when he is hurt or crying. A few other words were also used to represent his confession in response to other types of stimulus given to him. These were conducted by the teacher using consistent habituation stated in ECED."

The therapy conducted by the teachers in PAUD Psikologi UGM was based on the principles of inclusive education pointing to the principle of education for all, learning to live together, and as a preparation to blend with the society (Documentation on learning principle, 2 April 2015). The therapy applied to DN was conducted with consistency, cooperation, and support from his family. The goal of conditioning was to maintain DN's body to stay healthy and stable in order to make him study well and achieve developmental improvement.

\subsubsection{DN's social-emotional development post-therapy}

After undergoing therapy, DN showed significant improvement mainly on the aspect of responding to stimulus. MPS, a teacher in the school, stated in the interview that:

"DN now has the ability to respond to his friends in good manners as shown in his willingness to sit calmly with them while conducting learning activities, during lunchtime, and picture grouping activities. This is really different from when he first attended ECED when he could not sit tight with his friends and loves to run here and there (active). Moreover, DN has also started to queue by following the teachers' example." 
His ability to respond also manifests when teased by his friends, he tried seeking for patronage by looking for the teachers. This is one of the responses DN shows when feeling uneasy with his surroundings. Moreover, when he is angry, he responds by pinching and pulling his teacher's veil and when feeling sad he automatically cries (DN's Class observation).

Furthermore, DN's life skills also started to develop as observed in his squatting when trying to defecate. Even when he still cannot do the toilet training, at least $\mathrm{DN}$ is able to convey his condition as a response to the stimulus inside him (DN's Class observation).However, DN still has some weaknesses especially in a learning group activity such as role-playing, therefore, the teachers should focus on the area by giving special treatment with some instructions.

\section{2. $\quad$ Research Subject AT (TK Pedagogia UNY)}

\subsubsection{AT's Social-emotional Development Deficit}

Based on the interview with NW, the doctor of child growth and development in TK Pedagogia UNY, it was stated that:

"When joining this place AT experienced pretty much deficit symptoms such as speech delay, hyper-activeness, broken speeches, inability to stand straight, hands keep clenching, and repetition of the same word. From the emotional aspect, he showed the symptoms of unstable emotion by getting suddenly angry and hitting his friends. While studying he would do his own activity, and when his desires are not fulfilled, he would get angry and start hitting his teachers."

\subsubsection{The therapy obtained by AT in the school}

Three types of therapy were conducted on AT and they include occupational, speech, and play therapies. The information obtained by interviewing LDS supported the researcher's observation in the class stated that:

"The school conducted three therapies including speech, occupational, and play on AT at once through the process of modern psychology therapy. He was accompanied by a shadow teacher who guides him to talk word by word and asks him to repeat. He also attends therapy outside of school twice a week and was given stimulus continuously to aid his cerebral development."

AT received a medical therapy conducted by the doctor and modern psychology therapy by the psychologist and teachers. Moreover, a pharmacological therapy was conducted with the family's agreement in TK Pedagogia which is a child growth and development laboratory with the eminent program giving room for special needs children to learn together with friends in their age group. The cooperation of the psychologist, doctor, and parents makes it convenient to conduct integrated therapy. 


\subsubsection{AT's Social-emotional development post-therapy}

After receiving therapy in the school for a year, their improvement indicator observed include waving of his hands, and talking though unclear and not fluent. He has also improved control of his feelings and appreciating others. These were revealed in the interview with CU, a teacher in PAUD TK Pedagogia:

"AT is improving well. He now takes advice from his teacher and apologizes to his friends when he did something wrong. For example, yesterday he hit his friend and after being advised and explained by the teacher, he apologized."

This showed AT has already improved on the aspect of social-emotional development due to the therapy conducted by his teachers.

\subsection{Research Subject DW (PAUD Ahsanu 'Amala)}

4.3.1. DW's Social-emotional Development Deficit

Based on the interview with AS, a teacher in PAUD Ahsanu 'Amala, and daily notes documentation, DW's development deficit was observed to include the inability to blend in with groups, queue while conducting activities such as eating and going to the toilet, and urinating and defecating by herself. SA stated that:

"The hindrance observed when DW attended this school was that she had difficulties playing with friends in a group. She also has not grasped the concept of queuing while eating or using the toilet and needed to be accompanied while going to the toilet."

\subsubsection{The therapy obtained by DW in school}

The therapeutic method used in PAUD Ahsanu 'Amala consisted of modern psychology including play, habitual, speech, and modeling as well as religious therapies conducted by practicing Islamic prayer movements and memorizing prayer together with short Quran verses. They were conducted by psychologist and teachers. Based on the interview, Sa (teacher) stated that:

"There are a few forms of therapy conducted in this school and they include speech, play, habitual and modeling. This school also teaches on how to pray and make congregational prayer a habit to the student and use specifically as a religious therapy. In our opinion, congregation prayer plays an important role in developing children's social-emotional aspects and affects their temper control because it is a form of absolute submission to the creator. Memorizing prayers and Quran verses helps children develop their verbal qualification, especially those with speech delay hindrance."

\subsubsection{DW's Social-emotional development post-therapy}

From the observation, DW now has the ability to queue while getting food, greet, shake hands, and answer regular questions (DW's class observation, 9 February 2015). Through the interview, Sa (teacher) stated: 
"With the help of a teacher, DW now has the ability to do the things she was unable to do. However, she tends to be alone and can't blend in with the group, appreciate her friends, get angry, tend to cry, needs more protection and does not have the ability to feel guilty when doing something wrong."

One of the problems experienced by the children with autism is speech delay, and to achieve maximum result, speech therapy was conducted using the PAUD Ahsanu 'Amala method. This is different from the way it is conducted with other children. The therapist is required to be well prepared with deep knowledge of the symptoms and types of speech hindrance observed in children with autism.

\subsection{Research Subject $A D$ (TK ABA Nitikan)}

\subsubsection{AD's Social-emotional Development Deficit}

Based on the result of the interview with JS (teacher) and Daily notes analysis, $\mathrm{AD}$ was observed to often leave her class (going in and out of the class), being apathist, and dislike to play with things around her. Moreover, she also likes to tease, hit her friends, and play in another class other than hers.

\subsubsection{The therapy obtained by AD in school}

There are five types of therapy conducted in TK ABA Nitikan and the first is behavioral therapy which is conducted to help children control their behavior and actions while the second one is cognitive therapy conducted to help children feel, learn and make arguments, and to control emotions and feelings. This helps children with autism to think first before acting. The third is speech therapy which encourages parents to always communicate and converse on the feelings of the children and conducted by the family members showing support, love, and attention by giving them the time they need and listen to their story. The fourth is the occupational therapy where part of the children with autism have motoric development hindrance, especially lacking on the fine motor skill are helped to strengthen and fix the smooth muscle's coordination and ability. Moreover, the finger's muscle is a vital part to be trained especially as a preparation to learn to write and to do any work requiring fine motor skills (Interview with JS, a teacher in TK ABA Nitikan). The fifth is play therapy and according to the interview, JS stated that:

"Play therapy is a modified therapy useful in teaching the desired behavior through social interaction, concentration enhancement, and self-care. It is also used as a means of treatment and therapeutics to gain a new activity and skills related to the kid's needs. This approach spares the children from frustration, anger and discourages them from having self-confidence."

\subsubsection{AD's Social-emotional development post-therapy}

After experiencing a few therapies, AD shows an encouraging development. First, she is able to understand the rule applied in her classroom, especially those relating to games. Second, she is showing empathy to her friends, help them, and willing to play competitive games. Moreover, before the therapy, she 
eats while walking and often seen restless, but after the therapy, she eats while sitting down and in a calm state.

\section{Discussion}

This research was conducted to answer three main questions which include the type of social-emotional development deficit experienced by children with ASD, the therapeutic method used by each institution to improve social-emotional development on children with ASD, and the development achieved by the children after therapy. Therefore, the field data analysis gave three answers.

First, the children with ASD in four inclusive ECED in Yogyakarta generally have trouble in socializing, communicating, and behavioral aspects and these are related to their social and emotional development. The ability to socialize is one of the main skills for children and they do this by knowing their environment, physically and socially. It makes them understand and conduct their right and obligations according to their role and status in society. Moreover, socializing means learning and improving social behavioral patterns. Furthermore, communication skills, both verbal and non-verbal, are also important in a kid's everyday life because it allows them to convey a message to other people. Therefore, hindrance in communication aspect has the ability to alienate them from their surroundings.

This research, therefore, agrees with the findings of other works that children with ASD experience hindrance in communication, social, and behavioral aspects (Kaminsky \& Dewey, 2001; Travis \& Sigman, 1998; Cassel et al., 2007; Downs \& Smith, 2004). Karminski and Dewey (2001) showed children with ASD have trouble in social behavior, limited verbal communication ability, and aggressive behavior. The same was observed by Travis and Sigman (1998) when they posited that many hindrances occur in the interpersonal relationship of children with ASD such as social cognition and communication problems. Furthermore, Cassel et al. (2007) explained that main challenges include socialemotional function, sensory and communication issues. It is also hard for them to show a cooperative attitude to others, lack the ability to identify an emotion, and weird behaviors compared to children without ASD (Downs \& Smith, 2004). In addition, they do not have the ability to identify the right emotions and attitude easily and this affects their family (Meadan et al., 2010).

From the analysis, all of them were observed to have communication developmental deficit. According to the theory of Erikson (1997), socialemotional development in children aged 4-5 years old is indicated by embarrassment and doubt tendency. At this phase until a certain limit, children have started to stand, sit, walk, play, drink without parent's assistance; however, in their own case, they start to develop the feeling of embarrassment and doubt; hence, asking their parents for assistance and permissions. Therefore, it is important to build independence and reduce embarrassment and doubt in them and this can be achieved by treating them in good manners.

Second, the therapeutic method for social-emotional development conducted in inclusive ECED in Yogyakarta are divided into three and they include modern psychological, medical, and religious therapies. The modern psychological 
development therapy includes speech, occupational, behavioral, cognitive, play, and habitual therapy as well as modeling. However, medical therapy is conducted through occupational therapy and the use of the medical drug by doctors of child growth and development. Moreover, religious therapy includes making congregational prayer and Al-Quran verses recital a habit. Furthermore, the social-emotional development therapy conducted did not only involve the ECED institutions and parents but also establish a partnership with several parties, especially hospitals for child growth and development. In addition, making use of the surrounding environment becomes an effective method to enhance social-emotional development. The most important part of the therapy is the activities of their friends. This is necessary because the intercommunication between children with ASD and others without the hindrance helps them a lot. This is conformable with the discovery of Bellini et al. (2007) and Welsh et al. (2001). Bellini et al. (2007) showed the importance of school-based social skills intervention for children with ASD due to the sufficient human resource in teachers, psychologists, therapists, and the chance to interact with friends of the same age in a natural social environment. Therefore, teacher and school personnel are advised to give their full support to social skills intervention for children with ASD (Weish et al., 2001; Locke et al., 2019). This has the potential to give them the chance to build friendship, compete, share, and express their emotion with friends in their age group (Turnbull et al., 2006).

This research's discovery is relevant with social skills intervention classification conducted by McConnell (2002) where it was categorized into five including environmental modification as well as children's specific, comprehensive, friends mediated, and additional skills interventions. The environmental modification was conducted in a physical and social environment to make social interaction between children with ASD and their friends possible. The specific intervention was in the form of direct instruction relating to social attitude. Additional intervention made social interaction possible through related skills training while friends mediated intervention was the involvement of the kid's friends to make them respond and direct the social behavior of children with ASD. Lastly, the comprehensive intervention involves mixing other types to achieve the purpose of giving the children the adequate care they need.

Specifically, the two children from TK ABA Nitikan and PAUD Ahsanu 'Amala experienced religious-therapy intervention which is spiritual and involved the use of congregational prayer in the school in order to make the children with ASD gain focus on their activity based on absolute submission to the religion and social ruling in their environment. The congregational prayer has the ability to serve as a means of emotion control due to the aspect of submission to the creator and memorizing prayer and Al-Quran verses also help them improve their verbal language, especially for those with speech delay. Furthermore, in the latest psychological study, the concept of religious-therapy is the same as transpersonal psychology while modern psychology is related to biomedical therapy. This type of holistic thinking has the ability to establish a strong relationship between the mind and the body because the mental condition of an individual is manifested in the physical body. 
Third, the therapy conducted on the children with ASD gives off a significant impact on their social development in the aforementioned three aspects. This is in agreement with the findings of past research works (Hwang \& Hughes, 2000; Rogers, 2000; McConnell, 2002; Jones et al., 2006; Mahoney \& Perales, 2003; Bauminger, 2002). The positive impact of social skills intervention for children with ASD has been stated and restated by several works. Generally, the social intervention program shows positive results and also looks promising for their social and communication skills development. Furthermore, Rogers (2000) reported that children with ASD are responsive to the social skills intervention programs developed by researchers. In Rogers's opinion, support from the parents, environmental modification, and communication with the same aged friends are really effective.

Moreover, Bauminger (2002)'s evaluated the effectiveness of cognitive behavior therapy to facilitate children with ASD's social-emotional and social interaction understanding. The results of the research showed there are three development in three aspects of intervention including the dimension of social interaction where they undergo an improvement in how to start a positive social interaction after intervention, especially in sharing things, maintaining eye contact, and showing interest with friends in their age group; in the aspect of emotional knowledge, they showed more examples of specific and complex emotion compared to before intervention, and involved audience more often in different emotions.

\section{Conclusion}

This study concluded that ASD children in Yogyakarta Inclusive PAUD still experience obstacles in terms of socialization, communication, and behavior. Therefore, in dealing with these obstacles, it was utilized in both modern psychological, medical, and religious therapies, which contributed to children's emotional, social development. However, to obtain maximum effects, the intensity of the therapy in schools needs to be increased because the intervention currently conducted is not enough. The "thirty-hour teaching for 10-12 weeks" is not effective for their social development. Besides, the cooperation of the parents in the house is really important because their responsiveness makes it more possible for these children to learn more about the behaviors needed to improve their social skills.

This study only examines the therapy of emotional development in four early childhood institutions in Yogyakarta. Lots of empirical evidence obtained supported the discussion. However, the limitations need to be delivered, primarily related to the choice of research samples. Future research needs to consider a study sample of ASD children in schools with more diverse conditions and territorial area.

\section{Acknowledgements}

This article is based on the data and ideas from the dissertation submitted in fulfilment of Doctor's degree in Islamic Education, UIN Sunan Kalijaga 
Yogyakarta. The corresponding author would like to thank the second, third, and fourth authors for the discussions and various viewpoints.

\section{References}

Bauminger, N. (2002). The facilitation of social-emotional understanding and social interaction in high-functioning children with autism: Intervention outcomes. Journal of autism and developmental disorders, 32(4), 283-298.

Bellini, S. (2006). The development of social anxiety in high functioning adolescents with autism spectrum disorders. Focus on Autism and Other Developmental Disabilities, 21, 138-145. https://doi.org/10.1177/10883576060210030201

Bellini, S., Peters, J. K., Benner, L., \& Hopf, A. (2007). A meta-analysis of school-based social skills interventions for children with autism spectrum disorders. Remedial and Special Education, 28(3), 153-162. https://doi.org/10.1177/07419325070280030401

Bratton, S.C., Ray, D. and Rhine, T. (2005). The Efficacy of Play Therapy With Children: A Meta-Analytic Review of Treatment Outcomes (Professional Psychology: Research and Practice Copyright 2005 by the American Psychological Association. https:// doi.org/10.1037/0735-7028.36.4.376

Cassel, T. D., Messinger, D. S., Ibanez, L. V., Haltigan, J. D., Acosta, S. I., \& Buchman, A. C. (2007). Early social and emotional communication in the infant siblings of children with autism spectrum disorders: An examination of the broad phenotype. Journal of autism and developmental disorders, 37(1), 122-132. https://doi.org/10.1007/s10803-006-0337-1

Constantino, J., Lajonchere, C., Lutz, M., Gray, T., Abbacchi, A., \& McKenna, K. (2006). Autistic social impairment in the siblings of children with pervasive developmental disorders. The American Journal of Psychiatry, 163, 294-296. https:// doi.org/10.1176/appi.ajp.163.2.294

Creswell, J. W. (2008). Educational research: Planning, conducting, and evaluating quantitative and qualitative research (3rd ed.). New Jersey: Pearson Prentice Hall.

Creswell, J. W. (2013). Qualitative inquiry and research design: Choosing among five approaches (3rd ed.). Thousand Oaks, CA: Sage

Delphi, B. (2006). Pembelajaran Anak Berkebutuhan Khusus dalam Setting Pendidikan Inklusif [Learning of Children with Special Needs in the Setting of Inclusive Education]. Bandung: Refika Aditama.

Downs, A., \& Smith, T. (2004). Emotional understanding, cooperation, and social behavior in high-functioning children with autism. Journal of autism and developmental disorders, 34(6), 625-635. Doi:10.1007/s10803-004-5284-0

El Achkar, C. M., \& Spence, S. J., (2015). Clinical characteristics of children and young adults with co-occurring autism spectrum disorder and epilepsy. Epilepsy $\mathcal{E}$ Behavior, 47, 183-190. Doi:10.1016/j.yebeh.2014.12.022

Erikson, E. (1997). Persoanality Theories, Phychology Departement Shippensburg University.

Fine, M., Weis, L., Weseen, S., \& Wong, L. (2000). For whom? Qualitative research, representations, and social responsibilities. In N. K. Denzin \& Y. S. Lincoln (Eds.), Handbook of Qualitative Research (2nd ed., pp. 107-132). Thousand Oaks, CA: Sage Publications.

Gresham, F. M., Sugai, G., \& Horner, R. H. (2001). Interpreting outcomes of social skills training for students with high-incidence disabilities. Teaching Exceptional Children, 67, 331-344. https://doi.org/10.1177/001440290106700303 
Howlin, P., Mawhood, L., \& Rutter, M. (2000). Autism and developmental receptive language disorder-A follow up comparison in early adult life. II: Social, behavioural, and psychiatric outcomes. Journal of Child Psychology and Psychiatry, 41, 561-578. https://doi.org/10.1111/1469-7610.00643

Hume, K., Bellini, S., \& Pratt, C. (2005). The usage and perceived outcomes of early intervention and early childhood programs for young children with autism spectrum disorder. Topics in Early Childhood Special Education, 25, 195-207. https://doi.org/10.1177/02711214050250040101

Hwang, B., \& Hughes, C. (2000). The effects of social interactive training on early social communicative skills of children with autism. Journal of Autism and Developmental Disorders, 30, 331-343.

Jones, E. A., Carr, E. G., \& Feeley, K. M. (2006). Multiple effects of joint attention for children with autism. Behavior Modification, 30, 782-834. https://doi.org/10.1177/0145445506289392

Kaminsky, L., \& Dewey, D. (2001). Siblings relationships of children with autism. Journal of Autism and Developmental Disorders, 31(4), 399-410.

Kamps, D., Royer, J., Dugan, E., Kravits, T., Gonzalez-Lopez, A., Garcia, J., et al. (2002). Peer training to facilitate social interaction for elementary students with autism and their peers. Exceptional Children, 68(2), 173-187. https://doi.org/10.1177/001440290206800202

Landa, R. \& Garrett-Mayer, E. (2006). Development in infants with autism spectrum disorders: A prospective study. Journal of Child Psychology and Psychiatry, 47(6), 629-638. https://doi.org/10.1111/j.1469-7610.2006.01531.x

Liamputtong, P. (2009). Qualitative research methods (3rd ed.). Melbourne: Oxford University Press.

Locke, J., Rotheram-Fuller, E., Harker, C., Kasari, C., \& Mandell, D. S. (2019). Comparing a Practice-Based Model with a Research-Based Model of social skills interventions for children with autism in schools. Research in Autism Spectrum Disorders, 62, 10-17. doi:10.1016/j.rasd.2019.02.002

Mahoney, G., \& Perales, F. (2003). Using relationship-focused intervention to enhance the social-emotional functioning of young children with autism spectrum disorders. Topics in Early Childhood Special Education,23(2), 74-86. https://doi.org/10.1177/02711214030230020301

Matson, J. L., \& Wilkins, J. (2007). A critical review of assessment targets and methods for social skills excesses and deficits with autism spectrum disorders. Research in Autism Spectrum Disorders, 1, 28-37.

Matson, J. L., Matson, M. L., \& Rivet, T. T. (2007). Social-skills treatments for children with autism spectrum disorders: An overview. Behavior modification, 31(5), 682707. https://doi.org/10.1016/j.rasd.2006.07.003

McConnell, S. R. (2002). Interventions to facilitate social interaction for young children with autism: Review of available research and recommendations for educational intervention and future research. Journal of Autism and Developmental Disorders, $32,351-372$.

McMahon, L. J., Noll, R. B., Michaud, L. J., \& Johnson, J. C. (2001). Sibling adjustment to pediatric traumatic brain injury: a case-controlled pilot study. Journal of Head Trauma Rehabilitation, 16(6), 587-594. https://doi.org/10.1097/00001199200112000-00006

Meadan, H., Stoner, J. B., \& Angell, M. E. (2010). Review of literature related to the social, emotional, and behavioral adjustment of siblings of individuals with autism spectrum disorder. Journal of Developmental and Physical Disabilities, 22(1), 83-100. https://doi.org/10.1007/s10882-009-9171-7 
Osterling, J. A., Dawson, G., \& Munson, J. A. (2002). Early recognition of 1-year-old infants with autism spectrum disorder versus mental retardation. Development and Psychopathology, 14, 239-251. https://doi.org/10.1017/s0954579402002031

Otero, T. L., Schatz, R. B., Merrill, A. C., \& Bellini, S. (2015). Social Skills Training for Youth with Autism Spectrum Disorders. Child and Adolescent Psychiatric Clinics of North America, 24(1), 99-115. https://doi.org/10.1016/j.chc.2014.09.002

Pickles, A., Starr, E., Kazak, S., Bolton, P., Papanikolaou, K., Bailey, A., ... \& Rutter, M. (2000). Variable expression of the autism broader phenotype: findings from extended pedigrees. The Journal of Child Psychology and Psychiatry and Allied Disciplines, 41(4), 491-502. https:/ / doi.org/10.1111/1469-7610.00634

Pilowsky, T., Yirmiya, N., Doppelt, O., Gross- Tsur, V., \& Shalev, R. S. (2004). Social and emotional adjustment of siblings of children with autism. Journal of Child Psychology and Psychiatry, 45(4), 855-865.

Rogers, S. (2000). Interventions that facilitate socialization in children with autism. Journal of Autism and Developmental Disorders, 30, 399-409.

Rutter, M. (2000). Genetic studies of autism: From the 1970s into the millennium. Journal of Abnormal Child Psychology, 28, 3-14.

Siller, M. \& Sigmund, M. (2002). The behaviors of parents of children with autism predict the subsequent development of their children's communication. Journal of Autism and Developmental Disorders, 32(2), 77-89.

Simons, H. (2009). Case Study Research in Practice. London: Sage.

Singhi, P., Malhi, P., \& Dwarka, P. (2002). Psychological adjustment of siblings of children with disabilities. Journal of Personality and Clinical Studies, 18,9-18.

Starks, H., \& Trinidad, S. B. (2007). Choose your method: A comparison of phenomenology, discourse analysis, and grounded theory. Qualitative Health Research, 17(10), 1372- 1380. doi:10.1177/1049732307307031

Stoneman, Z. (2005). Siblings of children with disabilities: research themes. Mental Retardation, 43(5), 339-350.

Susanto, A. (2011). Perkembangan Anak Usia Dini [Early Childhood Development]. Jakarta: Kencana Prenada Media Group.

Tantam, D. (2000). Psychological disorder in adolescents and adults with Asperger syndrome. Autism, 4, 47-62. https://doi.org/10.1177/1362361300004001004

The Centers for Disease Control and Prevention (2016). Prevalence of ASDs. Retrieved July 21 from http://www.cdc.gov /ncbddd/autism/faq_prevalence.htm.

Torres, M. V. T., Cardelle-Elawar, M., Mena, M. J. B., \& Sánchez, A. M. M. (2003). Social background, gender and self-reported social competence in 11- and 12-year-old Andalusian children. Journal of Research in Educational Psychology, 1, 37-56.

Travis, L. L., \& Sigman, M. (1998). Social deficits and interpersonal relationships in autism. Mental Retardation and Developmental Disabilities Research Reviews, 4(2), 65-72. ttps://doi.org/10.1002/(sici)1098-2779(1998)4:2<65::aid-mrdd2>3.0.co;2$\mathrm{W}$

Trianes, M. V., \& Fernández-Figarés, C. (2001). Learning to be a person and live with others: A program for secondary school. Bilbao, Spain: Descleé de Brower.

Turnbull, A., Turnbull, R., Erwin, E., \& Soodak, L. (2006). Families, professionals, and exceptionality: positive outcomes through partnerships and trust (5th ed.). Upper Saddle River: Merrill/Prentice Hall.

Veenstra V.J., \& Cook, E. H. J. (2003). Genetics of childhood disorders: XLVI. autism, part 5: Genetics of autism. Journal of the American Academy of Child and Adolescent Psychiatry, 42, 116-118. https://doi.org/10.1097/00004583-200301000-00018 
Verte, S., Roeyers, H., \& Buysse, A. (2003). Behavioural problems, social competence and self-concept in siblings if children with autism. Child: Care, Health $\mathcal{E}$ Development, 29(3), 193-205. https://doi.org/10.1046/j.1365-2214.2003.00331.x

Vinanti, G., \& Salomone, E. (2015). Autism Spectrum Disorders. International Encyclopedia of the Sosial \& Behavioral Sciences, 275-281. https://doi.org/10.1016/B978-0-08097086-8.23230-3

Welsh, M., Park, R. D., Widaman, K., \& O'Neil, R. (2001). Linkages between children's social and academic competence:A longitudinal analysis. Journal of School Psychology, 39, 463-481. https://doi.org/10.1016/s0022-4405(01)00084-x

Wimpory, D. C., Hobson, R. P., Williams, J. M. G., \& Nash, S. (2000). Are infants with autism socially engaged? A study of recent retrospective parental reports. Journal of Autism and Developmental Disorders, 30, 525-536.

Zwaigenbaum, L., Bryson, S., Rogers, T., Roberts, W., Brian, J., \& Szatmari, P. (2005). Behavioral manifestations of autism in the first year of life. International Journal of Developmental Neuroscience, 23 , 143-152. https://doi.org/10.1016/j.ijdevneu.2004.05.001 